\title{
Research on the Development of College English Education in China under the Background of MOOC
}

\author{
Qing Song \\ School of Foreign Languages, Kunming University, Kunming, China \\ 932821517@qq.com
}

\begin{abstract}
Keywords: MOOC; English education; Chinese colleges; opportunities; challenges; coping strategies

Abstract. With the influence of elite universities and famous greats, MOOC brings unprecedented impact and challenge into traditional higher education mode by providing free online courses and personalized learning style. Facing the oncoming education revolution, English education of Chinese universities is the first to be affected. But crisis and opportunities coexist. On the one hand, a potential market in English teaching will emerge as people are eager to learn English; on the other hand, the present rigid teaching patterns of college English are becoming increasingly inappropriate since more flexible and multiple pathways for English study are available. Hence, educational policymakers, managers and lecturers in English should prepare against rainy days and take suitable countermeasures to avoid becoming obsolete in the MOOC age.
\end{abstract}

\section{Introduction}

MOOC is short for Massive Open Online Course [1]. MOOC was originally developed in the 1960s. In 2012, Stanford University, Harvard University and the Massachusetts institute of technology and other top universities invested tens of millions of dollars to build the Coursera, Udacity, EdX three online course platforms, launched by the school for free from the Internet, and made the high-quality goods curriculum teacher [2]. These movements have sparked a global wave of online education reform, and brought new insights into the university's education model, which has since become a global concern. MOOC will break the basic unchanged for hundreds of years of traditional education mode, encourage education into the era of 4A (something, anytime, anywhere, anything) [3]. It makes it possible for anyone at any time and space to accept any subject of education. MOOC to global much education researchers focuses on the impact of the university education. Many Chinese managers and education experts at the universities of the MOOC far-reaching significance on the education in the future have a sober understanding.

It is fair to say that without any discipline in a university, the English education of the Chinese university has its opportunities and challenges [4]. However, there is not enough discussion about how the Chinese university's English education should respond to the dramatic changes that MOOC is about to bring to the university's English education [5]. MOOC is a kind of brand-new education in the history of the world education mode. The reform of college English education in China is an important part of the transfer, and is well worth for English education workers to carry on the extensive discussion. This paper aims to further explore the opportunities, challenges and strategies faced by education in MOOC.

\section{The Opportunity of MOOC to College English Education in China}

Chinese College English Education will Benefit from the Excellent Education Resources of MOOC. MOOC is the biggest bright spots, because it is the education league of the world's leading universities. As a result, MOOC's excellent education resources are not matched by any independent university, which is one of the reasons why MOOC can have a worldwide impact.

MOOC will greatly improve the English learning environment of Chinese college students. It is well known that for a long time, Chinese university students lacked the good conditions for both the input and output of English. In terms of language input, the majority of college students are taught 
by Chinese teachers in the classroom, reading old textbooks and listening to audio recordings, etc., to learn English. Even if there is a chance to hear English speakers, most of them are limited in listening and speaking. Chinese college students have a poor chance of exporting English, and they don't have much chance to communicate directly with native English speakers. Some college students even shy away from using English to communicate with Chinese teachers and classmates. These factors are the main reasons for the low level of English proficiency in Chinese college students. MOOC is expected to make a significant difference in this situation. On MOOC platform, students can not only listen to foreign teachers teaching in their native language, they can also learn with teachers and classmates, do online text, voice and video communication. It has the extremely vital significance on improving Chinese students' English application ability.

In addition, the things MOOC brings to Chinese college students are not only a change in language learning environment, it also provides a broad space for Chinese college students to change their knowledge structure and enhance employment competitive power through the abundant high-quality course. Some students with solid base English can use English as the backing, and take suitable for their own professional courses on MOOC in order to become innovative talents with interdisciplinary knowledge or skills. Some students may also get a second degree in MOOC. For Chinese college students, English will return from an exam subject to the proper place of a practical language tool.

MOOC will Make the Chinese College English Education more of Personalization and Humanization. Because of the lack of education resources, the Chinese college's education has struggled to personalize and humanize. At present, the English education of the university in China still adopts the model of mass collective class. The English major is generally 30 people in a class, and the class of public English is composed of $50 \sim 100$ students. Under such circumstances, teachers' attention to the situation of individual English learning is limited. MOOC will make the Chinese college English education more of personalization and humanization in the following areas, as shown in Figure 1.

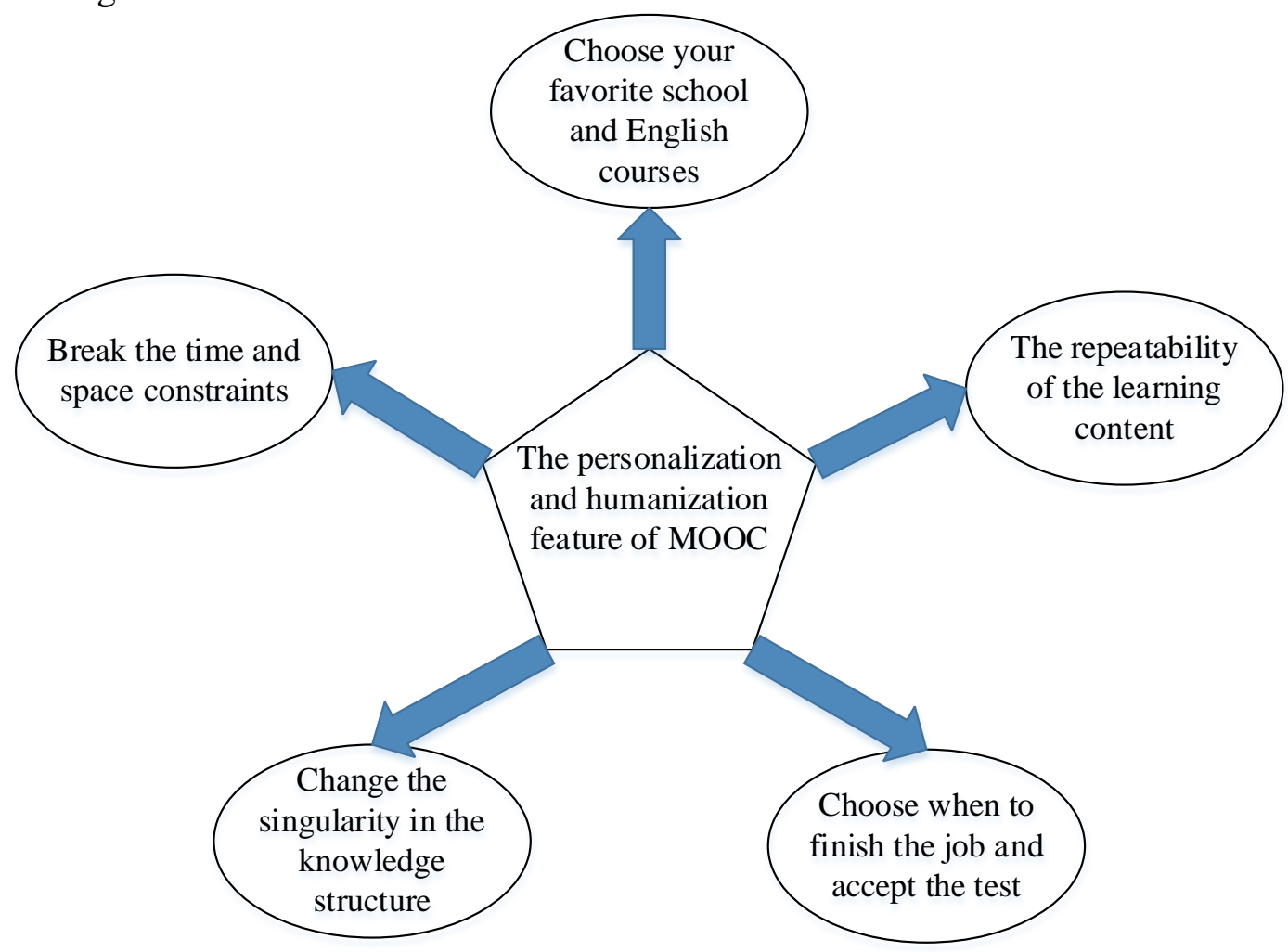

Figure 1. The personalization and humanization of MOOC 


\section{Challenges Facing Chinese College English Education in the Future}

China will Face the English Education Students' competition with Global Colleges in MOOC. MOOC is the online education alliance that breaks the boundaries, breaks the walls of the campus, and breaks the learning time and space and credits. The scale will be expanded and its operations will mature. It will only be a matter of time before the impact of the Chinese traditional college's student is made. In fact, the courses on MOOC are mostly made by masters of prestigious universities or excellent teaching teams, and most of the courses are now available for free. This is clearly a strategic decision to build a future customer base, establish a brand, and preempt the education market. The United States, Europe, and now Asia, all attract and compete for the important strategic goals of international students. If Chinese college English teachers can't design good and practical courses to keep students, some teachers may indeed be doomed.

The Ability of Chinese University English Teachers to Improve in many Ways is Urgent. The Promotion of Modern Educational Technology. At present, most of Chinese college English teachers still use simple PPT courseware in class, and play some audio and video information to English teaching. The education technology has been far from MOOC environment to meet the demand of teaching. In the context of MOOC and traditional education models, the teaching skills required by university English teachers will exceed the required skills required for traditional classroom teaching. They must be able to more skillfully to use computer technology to design courseware, organize and manage students' learning on the Internet, and receive feedback information of students in the learning process.

The Adjustment of Knowledge Structure. As a college English teacher in the MOOC era, it is obviously not enough to have good English professional skills. Chinese college English teachers should also have a broader and interdisciplinary knowledge in order to find a large number of information and curriculum suitable for students from the MOOC courses, and accurately and effectively guide different professional students to complete their learning tasks in MOOC.

The Enhancement of Ability to Design Quality Courses. Chinese college English education has used the English teaching materials wrote by the state education department's relevant experts in order to develop English teaching activities. These materials generally have matching reference books, teaching plan and PPT presentation courseware. In some ways, Chinese college English teachers are only the practitioners of the teaching process, not the designers. As a result, most Chinese college English teachers have a relatively weak curriculum. Chinese college English teachers should improve the designing ability of individual and teachers' team courses as soon as possible, and design enough excellent courses to participate in the competition of the college English education in MOOC.

The Improvement of the Ability to Distinguish and Integrate Network Teaching Resources. For Chinese college English teachers, how to distinguish the quality and integration of thousands of courses in MOOC is a whole new topic. Chinese college English teachers need to conduct research, analysis, classification and integration of these large materials libraries to provide advice for different groups of students to guide their studies. Therefore, Chinese college English teachers should be trained in this aspect and improve as soon as possible.

Challenges in the Management of College English Teaching. MOOC are new education patterns that are interwoven with the traditional education pattern. It will bring a lot of new education ideas and teaching advantages and it will inevitably lead to a lot of problems to be solved. For example, teaching management can cause a lot of trouble. If thousands of students in different regions in a number of different colleges take the English training courses, and some courses may be a language course at the college of other countries, the credit of the students, student status, and management of the examination results will be problems. How to coordinate the student management system of colleges around the world will test the wisdom of managers and system designers.

In addition, to ensure that the students' learning process on the MOOC platform is real and effective, preventing cheating in the exam is a difficult challenge for technicians to overcome. A 
Stanford university professor has created a class called "artificial intelligence introduction" on MOOC that once created a record of 160, 000 people worldwide. In the face of such a large group of students, the question of how to effectively supervise students' learning is a question worth investigating and must be solved.

Challenges Faced by College Students in the MOOC Platform. College students may face the challenge of learning English lessons in MOOC, as shown in Figure 2.

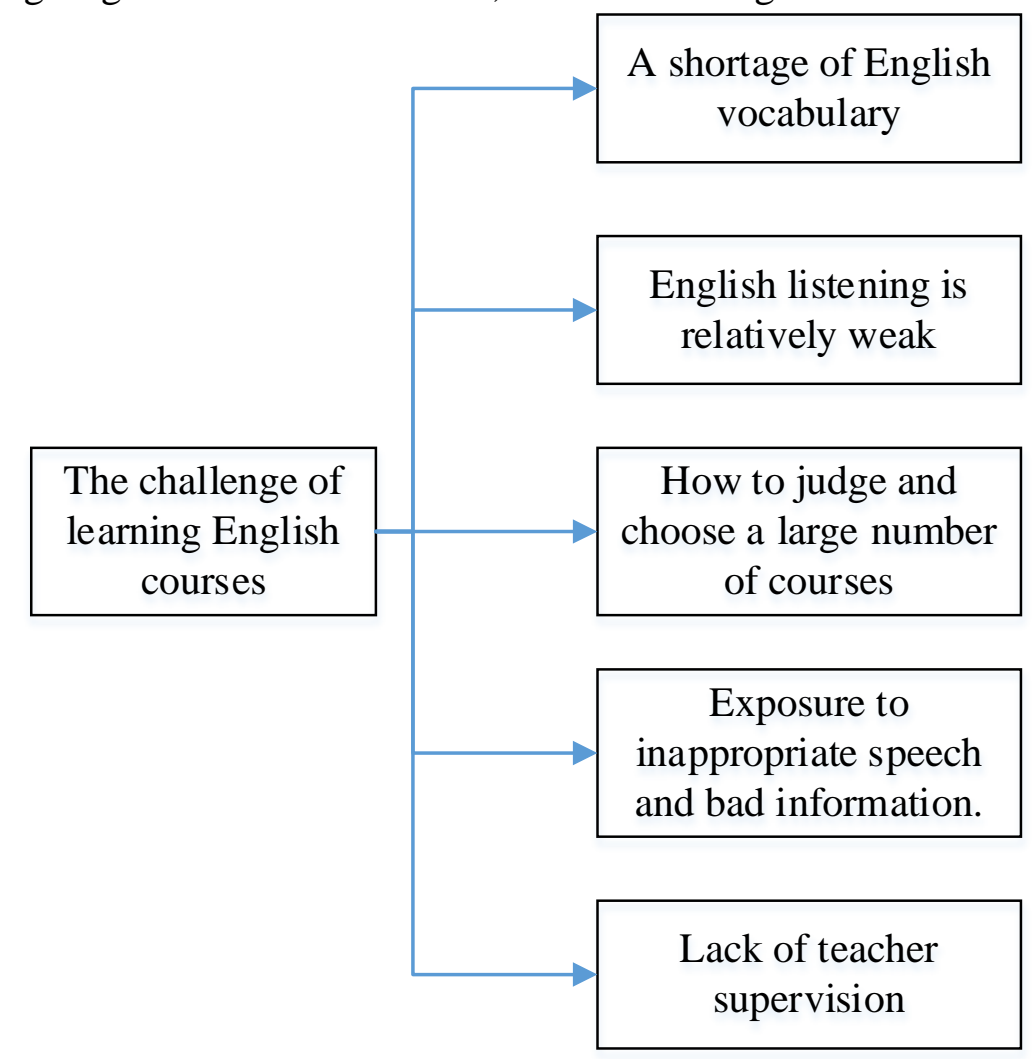

Figure 2. Challenges faced by college students in the MOOC platform

\section{Strategies of Chinese College English Education to Deal with MOOC}

Formulate Strategies and Plans for Addressing the Competition of Global University Students in Time. MOOC is both a challenge to China's traditional English education and a turnaround for many of the shortcomings of the Chinese college's education. Chinese college English teachers are aware of the trend of internationalization of education. When the college walls fall apart, the flow of fresh produce is bound to happen. When the loss of the original students in a college occurs, Chinese college English teachers can design better and more distinctive and more practical courses and more refined, more humanized service to keep the students after class and at the same time also can consider development in English teaching, courses related to Chinese culture, such as "Chinese tourism", "Chinese tongue", "martial arts" "Chinese medicine" and "the Chinese traditional culture", etc., to attract foreign students. In addition, there is also a huge potential for Chinese college English teachers in the education of foreign students.

Rapidly Improve the Teachers' modern Education Technology. The internationalization of the education and the popularity of the education are typical features of MOOC, where people can accept higher education in any place that has a network connection. In the age of MOOC, the number of college students is bound to increase greatly. Chinese college English teachers must be with the aid of computer technology to realize the task of teaching and management, especially using computer software to quickly generate questions, editing teaching audio and video, releasing and correcting the electronic homework, tracking student progress, analyzing the students' study effect. Learning to use a teaching system with artificial intelligence to reduce workload and improve teaching efficiency and quality is one of the key skills that Chinese college English 
teachers should master soon.

The Transformation of the Education Management Concept. The scarcity of population and poor education resources have never been considered by Chinese university management. The college entrance exam has so far determined the major events of our lives. But when the MOOC brings changes to education way, and the coming trend of the internationalization of higher education, it is difficult to avoid a struggle of teaching quality. In fact, hundreds of famous universities around the world have already kicked off the academic super world of the fittest in MOOC. Decision makers and managers of Chinese colleges, especially the policy makers and managers of education, should quickly transform their management concepts. The college English education concept, which is completely abandoned for the purpose of examination, makes the college English education more practical and more specialized. College English teachers should strengthen the training of modern education skill. Only greatly improve the college English teachers' operating ability to process computer system can make Chinese university English education teaching adapt the digital age in the future.

Students should be able to Make Good Use of the English Foundation for the Internationalization of Education. Chinese college students, planning to take some professional interdisciplinary courses of foreign universities, must consciously accumulate relevant professional English vocabulary, understand the conventions of professional language and strengthen reading on professional materials, which can be well integrated into the trend of the internationalization of higher education. The distinctive core competitiveness can be formed through mastering other professional knowledge and skills by using English. In addition to the accumulation of English vocabulary and the strengthening of the reading of professional English literature, English majors need to train more English listening skills to complete the course in MOOC. Moreover, Chinese college students should improve their ability of self-learning and self-control, and eliminate the influence of network bad information to achieve their learning goals on MOOC.

\section{Conclusion}

As the MOOC education model is inter-school, internationalization and globalization, its working language is mainly in English. Therefore, in this education revolution, college English education is bound to bear the brunt. On the one hand, people are more urgent to learn English, and the potential market of English teaching is broader. On the other hand, the way of learning English is more flexible and diverse, and the rigid model of Chinese college English teaching will become more inappropriate. In short, in the face of the challenges of MOOC education model, all teaching disciplines, including college English teaching, are faced with a transition from tradition to modernism. It can be said that opportunities and crises co-exist, This requires educational decision-makers, managers and every college English teacher to think seriously, take precautions, take appropriate measures as soon as possible. Only in this way can we gain a foothold in the future competition, achieve new development and avoid the embarrassing situation in the future.

\section{References}

[1] Yang Qian. Reforming Vocational English Education with Localization of MOOC [J]. Journal of Wuhan Polytechnic, 2015, 4: 61-63.

[2] Yang Xiufang, Li Haiyan. Research on English Teaching Model of Higher Vocational Education Based on MOOC [J]. Journal of Higher Education, 2015, 23: 171-172.

[3] Zhou Jialin. The Opportunities, Challenges and Strategies for English Education of Chinese Universities in the MOOC Age [J]. Journal of Zhaoqing University, 2014, 35(6): 82-87.

[4] Li Mei, Fu Ge, Lu Mingzhao. A Study of College English Teachers' Professional Development in MOOC Era [J]. Times Agricultural Machinery, 2016, 43(12): 115-116.

[5] Yang Qian. Exploration and Countermeasures of China 's Vocational English Education Reform under MOOC [J]. Education Teaching Forum, 2016, 27: 144-145. 